\title{
Efficacy of recommended drugs against soil transmitted helminths: systematic review and network meta-analysis
}

\author{
Wendelin Moser, ${ }^{1,2}$ Christian Schindler, ${ }^{2,3}$ Jennifer Keiser ${ }^{1,2}$
}

${ }^{1}$ Department of Medical

Parasitology and Infection

Biology, Swiss Tropical and

Public Health Institute, PO Box,

CH-4002 Basel, Switzerland

${ }^{2}$ University of Basel, Basel,

Switzerland

${ }^{3}$ Department of Epidemiology and Public Health, Swiss

Tropical and Public Health

Institute, PO Box, CH-4002

Basel, Switzerland

Correspondence to: J Keiser jennifer.keiser@unibas.ch

Additional material is published online only. To view please visit the journal online.

Cite this as: $B M J$ 2017;358:j4307 http://dx.doi.org/10.1136/bmj.j.4307

Accepted: 11 September 2017

\author{
ABSTRACT \\ OBJECTIVE \\ To evaluate efficacies of anthelmintic drugs against \\ soil transmitted helminths in terms of cure rates and \\ egg reduction rates.
}

DESIGN

Systematic review and network meta-analysis.

DATA SOURCES

PubMed, ISI Web of Science, Embase, ScienceDirect, the Cochrane Central Register of Clinical Trials, and the World Health Organization library database from 1960 until 31 December 2016.

\section{STUDY SELECTION}

Randomised controlled trials evaluating the efficacy of a single dose regimen of albendazole, mebendazole, levamisole, and pyrantel pamoate against Ascaris lumbricoides, hookworm (Necator americanus and Ancylostoma duodenale) and Trichuris trichiura. The primary outcomes included cure rates analysed by network meta-analysis with mixed logistic regression models and egg reduction rates with mixed linear models.

\section{RESULTS}

55 and 46 randomised controlled trials were included in the analysis of cure rates and egg reduction rates, respectively. All drugs were highly efficacious against A lumbricoides. Albendazole showed the highest efficacy against hookworm infections with a cure rate of $79.5 \%$ (95\% confidence interval $71.5 \%$ to $85.6 \%$ ) and an egg reduction rate of $89.6 \%$ ( $81.9 \%$ to $97.3 \%$ ). All drugs had low efficacy against $T$ trichiura, with mebendazole showing the highest cure rate of $42.1 \%$ (25.9\% to $60.2 \%$ ) and egg reduction rate of $66.0 \%$ (54.6\% to $77.3 \%$ ). Estimates for the years 1995 and 2015 showed significant reductions in efficacy of albendazole against $T$ trichiura: by 2015 the egg reduction rates fell from $72.6 \%(53.7 \%$ to $91.5 \%)$ to

\section{WHAT IS ALREADY KNOWN ON THIS TOPIC}

The current strategy against soil transmitted helminths is preventive chemotherapy, mainly with albendazole, mebendazole, and, to a lesser extent, levamisole and pyrantel pamoate

A previous meta-analysis presented summary estimates of cure rates of these drugs based on a small number of randomised controlled trials

\section{WHAT THIS STUDY ADDS}

The study provides up to date estimates of cure rates and egg reduction rates with network meta-analysis

The two most commonly used drugs have shortcoming in their efficacy profile: mebendazole has low efficacy against hookworm and albendazole and mebendazole show low performance against $T$ trichiura

Efficacy albendazole and mebendazole against $T$ trichiura has decreased over the past decades
$43.4 \%(23.5 \%$ to $63.3 \% ; P=0.049)$ and the cure rates fell from $38.6 \%(26.2 \%$ to $52.7 \%)$ to 16.4 (7.7\% to $31.3 \% ; \mathrm{P}=0.027)$.

\section{CONCLUSIONS}

All four currently recommended drugs show limitations in their efficacy profile. While only albendazole showed good efficacy against hookworm infection, all drugs had low efficacy against $T$ trichiura. The decrease in efficacy of albendazole against $T$ trichiura over the past two decades is of concern. The findings indicate the need for strengthening efforts to develop new drug treatments, with a particular focus on drugs against $T$ trichiura.

\section{Introduction}

Soil transmitted helminthiasis is caused by infections with the nematode worm Ascaris lumbricoides, the hookworms Necator americanus and Ancylostoma duodenale, and Trichuris trichiura. An estimated 5.3 billion of people are at risk, while 1.5 billion are infected with at least one of the soil transmitted helminths. ${ }^{1}$ Despite a global decline in infections, prevalence remains high in Asia, followed by sub-Saharan Africa and Latin America. ${ }^{1} A$ lumbricoides and $T$ trichiura infections particularly affect preschool and school aged children, while hookworm infections are more prevalent in adults. Infected people predominantly live in poor conditions in the least developed countries, where households lack adequate facilities and clean water. Morbidity correlates with the number of worms harboured by infected individuals. While light infections commonly remain asymptomatic, moderate and heavy infections cause severe morbidity, ${ }^{2}$ including growth stunting, intellectual impairment, cognitive and educational deficits, malnutrition, and iron deficiency anaemia. ${ }^{3}$ In 2015, the global burden of infections with soil transmitted helminths was estimated at 3.4 million disability adjusted life years (DALYs). ${ }^{4}$

The goal of the World Health Organization (WHO) is to reduce the prevalence of moderate and heavy infections with soil transmitted helminths in preschool and school aged children to below $1 \%$ by $2020 .^{5-7}$ To achieve this goal, school aged children in endemic areas are regularly treated in so called preventive chemotherapy programmes. ${ }^{58}$ In 2015, about 573 million children received preventive chemotherapy against soil transmitted helminths, corresponding to a global coverage of $59.5 \%$. $^{9}$ The ultimate target is to cover at least $75 \%$ of school aged children in need of treatment. ${ }^{6}$ Albendazole, mebendazole, levamisole, and pyrantel pamoate are currently on the WHO list of essential medicines for the treatment of such infections, ${ }^{67}$ while the two 
benzimidazoles-albendazole and mebendazoleare the most widely used drugs in preventive chemotherapy programmes. $^{8}$

The efficacy of albendazole, mebendazole, and pyrantel pamoate has been assessed in a systematic review for different dose regimens ${ }^{10}$ and by means of meta-analysis of randomised controlled trials for single doses. ${ }^{11}$ Albendazole, mebendazole, and pyrantel pamoate had high efficacy against $A$ lumbricoides in terms of cure rates. Only albendazole was found to be efficacious in single dose regimen against hookworm (cure rate $72 \%$ ). Both albendazole and mebendazole had unsatisfactory results against $T$ trichiura at single doses with cure rates of $28 \%$ and $36 \%$, respectively. ${ }^{11}$ Of concern, recent results from randomised trials on Pemba Island (Tanzania) showed even lower cure rates for albendazole (2.6\%) and mebendazole (11.8\%) against $T$ trichiura. ${ }^{12}$

We updated the findings from the two systematic reviews, ${ }^{10} 11$ including new evidence and applying network meta-analysis methods. The comparison of intervention effects among randomised controlled trials with conventional meta-analysis is limited by the constraint that only drugs tested in the same study can be compared. ${ }^{11}$ In contrast, network meta-analysis draws strength from direct and indirect comparisons through common comparators (such as placebo). Furthermore, multiple drugs can be compared and ranked. ${ }^{13-17}$ In addition, for the first time we metaanalysed egg reduction rates, the standard key parameter for drug efficacy. ${ }^{18}$ Our analysis provides current evidence on anthelmintic drug efficacy, which is of considerable relevance to policy makers as they call for an adaptation of current treatment guidelines.

\section{Methods}

\section{Search strategy and selection criteria}

This review and meta-analysis is based on the Preferred Reporting Items for Systematic Reviews and Meta-Analysis (PRISMA) extension statement for network meta-analysis. ${ }^{19}$ The study protocol is provided in appendix 1 . We conducted an electronic literature search on PubMed, ISI Web of Science, Embase, ScienceDirect, the Cochrane Central Register of Clinical trials, and the WHO library database. All studies from 1960 until 31 December 2016 were considered. The search was not restricted to any language, and, in case of non-English articles, native speakers were consulted for full text translations. The triple MeSH search terms included "albendazole", "mebendazole", "levamisole", and "pyrantel pamoate" combined with either "trial", "study", or "case report” and “Ascaris lumbricoides”, "ascariasis”, "hookworm”, "Ancylostoma duodenale”, “Necator americanus”, "Trichuris trichiura”, "trichuriasis”, or "soil-transmitted helminths" (table A, appendix 1).

To be eligible for inclusion, studies had to be level 1 randomised controlled trials (https://www.elsevier. com/__data/promis_misc/Levels_of_Evidence.pdf) that reported the efficacy against $A$ lumbricoides, hookworm, and $T$ trichiura in terms of cure rates, egg reduction rates, or both. For this review we selected randomised controlled trials that included at least one treatment arm of the currently recommended 71020 single dose regimens of albendazole (400 mg), mebendazole(500mg), levamisole( $80 \mathrm{mg}$ or $2.5 \mathrm{mg} / \mathrm{kg}$ ), or pyrantel pamoate $(10 \mathrm{mg} / \mathrm{kg})$. There were no age restrictions. Studies were excluded if they were not randomised controlled trials, used different drug regimens (such as multiple doses or different drug regimens), or combined different drugs or if the followup was shorter than one or longer than six weeks.

\section{Patient involvement}

No patients were involved in setting the research question or the outcome measures, nor were they involved in developing plans for design or implementation of the study. No patients were asked to advise on interpretation or writing up of results. There are no plans to disseminate the results of the research to study participants or the relevant patient community. We did not evaluate whether the studies included in the review had any patient involvement.

\section{Data extraction and assessment of risk bias}

From each eligible randomised controlled trial we extracted number of infected participants at baseline, number of cured participants at follow-up, mean number of eggs at baseline, mean number of eggs at follow-up, percentage of egg reduction, measure of central tendency (arithmetic, geometric, or not described), information on the number of treatment arms, number of eligible treatment arms, year of publication, country, diagnostic method, age range, and time between treatment and follow-up.

Two independent reviewers (WM and JK) screened titles and abstracts for potential studies. When articles met the inclusion criteria, the entire manuscripts were scrutinised, and, for eligible trials, the data were extracted independently by the same reviewers. All included trials were assessed for quality by two different methods: that described by Jadad and colleagues, ${ }^{21}$ with scores ranging between 1 (lowest level) and 5 (highest level), and according to the Cochrane Collaboration Handbook (table A in appendix 2). ${ }^{22}$ The latter criteria assess studies for risk of bias in six different domains: random sequence generation, allocation concealment, blinding of participants and personnel, blinding of outcome assessment, incomplete outcome data, and selective reporting. Each domain is categorised into low, high, or unclear risk of bias. In case of discrepancies over extraction of data or scoring of the study quality, a third person (CS) was involved and the results discussed until consensus was reached.

\section{Data synthesis and statistical analysis}

The advantage of a network meta-analysis is the simultaneous combination of direct and indirect estimates of the treatment effect in one analysis. In data from clinical trials with direct estimates for drug A $v$ B and other trials comparing A $v$ C, we can estimate the relative treatment effect for $\mathrm{B} V \mathrm{C}$ and 
all three drugs can be ranked. ${ }^{13} 23$ To illustrate the network geometry, we have provided a separate plot for cure rates and egg reduction rates (fig 1). ${ }^{23}$ For the network meta-analysis of the cure rates, we used a method proposed by Kessels and colleagues. ${ }^{24}$ The method consists of rebuilding the original datasets based on sample sizes and case numbers retrieved from the publications. All datasets from studies with one, two, or more treatment arms were then pooled, and mixed logistic regression models were applied to the final pooled dataset. With this method even studies with only one eligible treatment arm can be included. The models included treatment as a fixed factor and random effects for studies and for treatment arms within studies. To mimic meta-regression analysis, we additionally included the respective regressor variable and its interactions with the treatments.

We recorded all egg reduction rates directly from the articles and used mixed linear models for the metaanalysis of these rates. These models included the fixed factors treatment, infection intensity (dichotomised as above versus below median of baseline egg counts), measure of central tendency (arithmetic mean, geometric mean, or not described), and random effects for studies. We considered baseline infection intensity to increase precision and to achieve approximate normality of regression residuals.

Table 1 shows the average cure rates and egg reduction rates per treatment derived from the underlying regression models as marginal estimates. We presented one sided 95\% confidence intervals if the limits of the respective two sided interval exceeded 0 or $100 \%$. We carried out one to one comparisons of cure rates and egg reduction rates by looking at the differences of the respective regression coefficients (fig 2). In the case of cure rates we used exponentiation to convert these differences into odds ratios. We also conducted a simple, pairwise meta-analysis of cure rates for the one to one comparison using the command metan in Stata. Table C in appendix 2 and fig B in

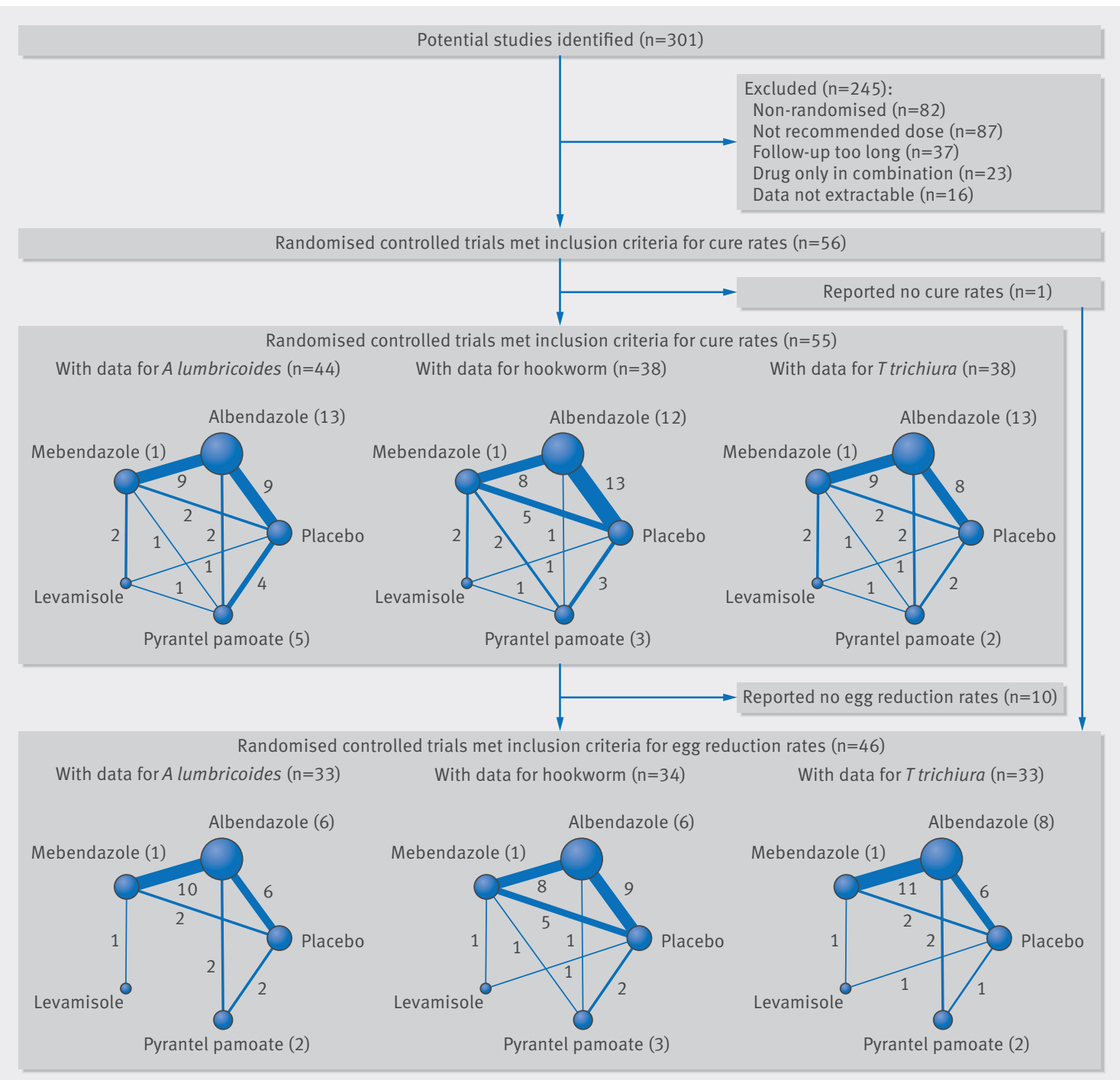

Fig 1 | Flowchart and network showing procedure for identification of relevant publications. Circular nodes show each treatment with circle size indicating amount of respective evidence and numbers in brackets indicating number of pooled studies with only one eligible treatment arm. Weight of line and number on line indicate number of direct treatment comparisons within same study 


\begin{tabular}{|c|c|c|c|c|c|c|}
\hline \multirow[b]{2}{*}{ Treatment } & \multicolumn{3}{|l|}{ Cure rates } & \multicolumn{3}{|c|}{ Egg reduction rates } \\
\hline & $\begin{array}{l}\text { No of included } \\
\text { studies }\end{array}$ & $\begin{array}{l}\text { No of included } \\
\text { participants }\end{array}$ & Rate $(95 \% \mathrm{Cl})$ & $\begin{array}{l}\text { No of included } \\
\text { studies }\end{array}$ & $\begin{array}{l}\text { No of included } \\
\text { participants }\end{array}$ & Rate $(95 \% \mathrm{Cl})$ \\
\hline \multicolumn{7}{|l|}{ A lumbricoides } \\
\hline Placebo & 14 & 842 & 12.7 (6.7 to 22.7) & 9 & 525 & 20.7 (14.7 to 26.7) \\
\hline Albendazole & 34 & 3360 & $95.7^{\star \star \star}(93.2$ to 97.3$)$ & 26 & 2854 & $98.5^{* \star *}$ (94.9 to 100.0$)$ \\
\hline Mebendazole & 13 & 1548 & $96.2^{\star \star \star}(92.3$ to 98.1$)$ & 13 & 1529 & $98.0^{\star \star *}(94.0$ to 100.0$)$ \\
\hline Levamisole & 2 & 149 & $97.3^{\star * \star}(84.2$ to 99.6$)$ & 1 & 125 & $96.4^{\star * *}(82.3$ to 100.0$)$ \\
\hline Pyrantel pamoate & 11 & 1374 & $92.6^{\star \star \star}(85.6$ to 96.3$)$ & 6 & 284 & $94.3^{\star \star *}(88.3$ to 100.0$)$ \\
\hline Total & 44 & 7273 & - & 33 & 5137 & - \\
\hline \multicolumn{7}{|l|}{ Hookworm } \\
\hline Placebo & 18 & 1309 & 15.2 (9.3 to 23.9) & 14 & 1046 & $16.2(5.3$ to 27.1$)$ \\
\hline Albendazole & 30 & 3104 & $79.5^{\star \star \star}(71.5$ to 85.6$)$ & 26 & 2839 & $89.6^{\star \star \star}(81.9$ to 97.3$)$ \\
\hline Mebendazole & 14 & 2305 & $32.5^{*}(20.8$ to 46.9$)$ & 14 & 2263 & $61.0^{\star \star \star}(52.0$ to 69.9$)$ \\
\hline Levamisole & 2 & 230 & 10.3 (2.4 to 35.2) & 1 & 202 & $61.8^{*}(30.3$ to 93.3$)$ \\
\hline Pyrantel pamoate & 7 & 230 & $49.8^{\star \star}(29.5$ to 70.1$)$ & 5 & 144 & $71.9^{\star \star \star}(54.7$ to 89.0$)$ \\
\hline Total & 38 & 7178 & - & 34 & 6494 & - \\
\hline \multicolumn{7}{|l|}{$T$ trichiura } \\
\hline Placebo & 11 & 1417 & $8.6(4.1$ to 17.1$)$ & 28 & 1049 & 19.2 (6.9 to 31.4$)$ \\
\hline Albendazole & 33 & 4432 & $30.7^{\star \star \star}(21.0$ to 42.5$)$ & 29 & 3407 & $49.9^{\star \star \star}(39.0$ to 60.6$)$ \\
\hline Mebendazole & 13 & 2514 & $42.1^{\star \star \star}(25.9$ to 60.2$)$ & 14 & 2507 & $66.0^{\star \star *}(54.6$ to 77.3$)$ \\
\hline Levamisole & 2 & 203 & 29.5 (6.1 to 72.9$)$ & 1 & 197 & 28.3 (6.7 to 49.8) \\
\hline Pyrantel pamoate & 6 & 275 & $20.2(7.3$ to 44.7$)$ & 4 & 158 & $47.5^{\star \star}(25.5$ to 69.6$)$ \\
\hline Total & 38 & 8841 & - & 33 & 7318 & - \\
\hline
\end{tabular}

appendix 3 show the respective summary odd ratios, $\mathrm{I}^{2}$, and $\tau^{2}$ statistics, where they are compared with the corresponding odd ratio estimates from network metaanalysis.

In a second stage, we stratified analysis for cure rates and egg reduction rates according to continent, place of the study, sensitivity of diagnostic method, quality of the study, length of follow-up, intensity of infection at baseline, and year of publication (see tables D-J in appendix 2). By letting the treatment interact in the mixed regression model separately with study size and year, we estimated cure rates and egg reduction rates

\section{A lumbricoides}

Albendazole $v$ mebendazole Albendazole $v$ levamisole Albendazole $v$ pyrantel pamoate Mebendazole $v$ levamisole Mebendazole $v$ pyrantel pamoate Levamisole $v$ pyrantel pamoate Hookworm

Albendazole $v$ mebendazole Albendazole $v$ levamisole Albendazole $v$ pyrantel pamoate Mebendazole $v$ levamisole Mebendazole $v$ pyrantel pamoate Levamisole $v$ pyrantel pamoate T trichiura

Albendazole $v$ mebendazole Albendazole $v$ levamisole Albendazole $v$ pyrantel pamoate Mebendazole $v$ levamisole Mebendazole $v$ pyrantel pamoate Levamisole $v$ pyrantel pamoate 0.01
Odds ratios for cure rates $(95 \% \mathrm{Cl})$

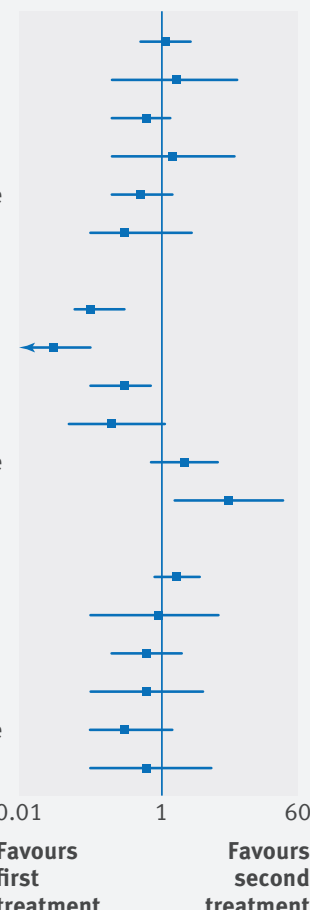
60

treatment
Odds ratios for cure rates $(95 \% \mathrm{Cl})$

1.1 (0.5 to 2.5$)$ $1.6(0.2$ to 11.3$)$ 0.6 (0.2 to 1.3$)$ 1.4 (0.2 to 10.3$)$ 0.5 (0.2 to 1.4$)$ 0.3 (0.1 to 2.6 )

$0.1(<0.1 \text { to } 0.3)^{\star \star \star *}$ $<0.1$ ( $<0.1$ to 0.1$)^{\star \star \star \star}$ $0.3(0.1 \text { to } 0.7)^{\text {** }}$ 0.2 (<0.1 to 1.1$)$ 2.1 (0.7 to 6.0) $8.6(1.5 \text { to } 50.0)^{\star}$

1.6 (0.8 to 3.3$)$ 0.9 (0.1 to 6.2) 0.6 (0.2 to 1.9$)$ 0.6 (0.1 to 3.8 ) 0.3 (0.1 to 1.4 ) 0.6 (0.1 to 4.9 ) treatmen

Fig 2 | Drug comparison based on network meta-analysis. Odds ratios for one to one comparisons of cure rates and difference for one to one comparisons of egg reduction rates are based on network meta-analysis for each drug and infection ( $\left.{ }^{\star} P<0.05, * \star P<0.01, * \star \star P<0.001\right)$ 
for small $(\mathrm{n}=30)$ and large $(\mathrm{n}=300$; table $\mathrm{K}$ in appendix 2) studies and for years 1995 and 2015 (table L in appendix 2), to examine publication bias and evaluate the potential trends of efficacy over time.

We assessed the consistency between estimated odd ratios from direct and indirect comparisons by adding indicator variables for the two respective parallel treatments to the mixed logistic regression models. The difference of their regression coefficients was exponentiated to obtain the ratio between the odds ratio from direct and the odds ratio from indirect comparison (referred to as ratio of odds ratios). The two variables were obtained as the product of the respective treatment indicator variable and the indicator variable for studies that compared both treatments directly. The ratio of odds ratios (and 95\% confidence intervals) measuring inconsistency between direct and indirect estimates are shown in appendix 3 (fig C). All analyses were done with STATA version 14.0 (StataCorp, College Station, TX, USA).

\section{Results \\ Characteristics of included studies and bias assessment}

We identified 301 potential studies of albendazole, mebendazole, levamisole, and pyrantel pamoate for treating soil transmitted helminth infections (fig 1). From these, we excluded 245: 82 were not randomised, 87 used a different dose regimen, 37 had follow-up longer than six weeks, 23 used only drug combinations, and data were not extractable from 16 (table B in appendix 2). From the 56 remaining studies, one included only egg reduction rates, while 10 did not report egg reduction rates. $\mathrm{A}$ total of 44 studies had data on cure rates against $A$ lumbricoides, and 38 presented data on hookworm and $T$ trichiura. For the analysis of egg reduction rates we included 34 studies for hookworm and 33 for A lumbricoides and $T$ trichiura. Studies including treatments consisting of placebo and albendazole and albendazole and mebendazole were most common. The inconsistency plot showed considerable differences between odd ratios of cure from direct and indirect comparisons for some of the drug pairs (fig $C$ in appendix 3), but none of these differences reached significance.

The percentages of studies in the lowest categories for risk of bias were $41.1 \%$ for random sequence generation, $30.4 \%$ for allocation concealment, and $51.8 \%$ for incomplete outcome data. The percentage of studies in the highest category for risk of bias was largest for blinding of participants and personnel (25.6\%). The category of unclear risk was largest in all criteria other than "incomplete outcome data." This was especially pronounced among studies published before the year 2000 (table $\mathrm{M}$ in appendix 2).

\section{Drug efficacy against $A$ lumbricoides}

We evaluated 44 studies with an average Jadad score of 2.5 and a total of 7273 participants positive for $A$ lumbricoides (table $\mathrm{N}$ in appendix 2 gives detailed numbers) to evaluate the effect of the four anthelmintic drugs against $A$ lumbricoides (fig 1). Pooled estimates were based on 19 studies with only one treatment, ${ }^{25-43}$ 22 studies with two treatments, ${ }^{1243-63}$ and three studies with three eligible treatments. ${ }^{64-66}$

The four anthelmintic drugs investigated showed highly significant superiority (all $\mathrm{P}<0.001$ ) over placebo (the average cure rate with placebo was $12.7 \%$ (95\% confidence interval $6.7 \%$ to $22.7 \%$; table 1). Estimated average cure rates were 95.7\% (93.2\% to $97.3 \%)$ for albendazole, 96.2\% (92.3\% to $98.1 \%)$ for mebendazole, $97.3 \%$ (84.2\% to 99.6\%) for levamisole, and $92.6 \%$ (85.6\% to $96.3 \%)$ for pyrantel pamoate. There were no significant differences among the four treatments in the one to one comparison (fig 2).

Thirty three studies reported egg reduction rates $^{12} 2526293132$ 34-38 43-49 5152 54-62 646667 (fig 3). All treatment arms showed significantly higher rates $(\mathrm{P}<0.001)$ than placebo $(20.7 \%$, 95\% confidence interval $14.7 \%$ to $26.7 \%$; table 1 ), while there were no significant differences between the rates with the four treatments (fig 2). The highest estimated egg reduction rate $(98.5 \%, 94.9 \%$ to $100.0 \%)$ was for albendazole, followed by $98.0 \%$ (94.0 to 100.0) for mebendazole, $96.4 \%$ (82.3 to 100.0) for levamisole, and $94.3 \%$ (88.3 to 100.0$)$ for pyrantel pamoate.

\section{Drug efficacy against hookworm}

For estimating the drug efficacy against hookworm, we looked at data from 7178 individuals from 38 studies (table 1; table $\mathrm{N}$ in appendix 2) with an average Jadad score of 2.8. Pooled estimates included 12 studies with one treatment, ${ }^{25} 2630-3234363842436821$ studies with two treatments, ${ }^{12} 4344$ 46-58 $626368-70$ and five studies with three treatments. ${ }^{64-667172}$

The cure rate was $15.2 \%$ (95\% confidence interval $9.3 \%$ to $23.9 \%$ ) for placebo (table 1 ). The rate with levamisole $(10.3 \%, 2.4 \%$ to $35.2 \%)$ did not differ significantly from the placebo rate, but was significantly higher with albendazole $(79.5 \%, 71.5 \%$ to $85.6 \%$; $\mathrm{P}<0.001)$, mebendazole $(32.5 \%, 20.8 \%$ to $46.9 \% ; \mathrm{P}=0.011)$, and pyrantel pamoate $(49.8 \%$, $29.5 \%$ to $70.1 \% ; \mathrm{P}=0.001)$. The one to one comparison of cure rates showed a strongly increased odds of cure after the administration of albendazole compared with mebendazole $(\mathrm{P}<0.001)$, levamisole $(\mathrm{P}<0.001)$, and pyrantel pamoate ( $\mathrm{P}=0.005$, fig 2$)$. The odds for levamisole were significantly lower than the odds for pyrantel pamoate $(\mathrm{P}=0.016)$.

We used data from 34 studies $^{12252630-32343638434446-49}$ 51 52 54-58 $626466-72$ (fig 3) to determine an egg reduction rate of $16.2 \%$ (95\% confidence interval $5.3 \%$ to $27.1 \%$ ) for placebo, which was significantly lower than the rates for all active treatments (table 1). Albendazole had the highest average rate of $89.6 \%(81.9 \%$ to $97.3 \%)$, followed by pyrantel pamoate $(71.9 \%, 54.7 \%$ to $89.0 \%)$, levamisole $(61.8 \%, 30.3 \%$ to $93.3 \%)$, and mebendazole $(61.0 \%, 52.0 \%$ to $69.9 \%)$. The one to one comparison showed a significant difference between albendazole and mebendazole $(\mathrm{P}<0.001$, fig 2$)$. 


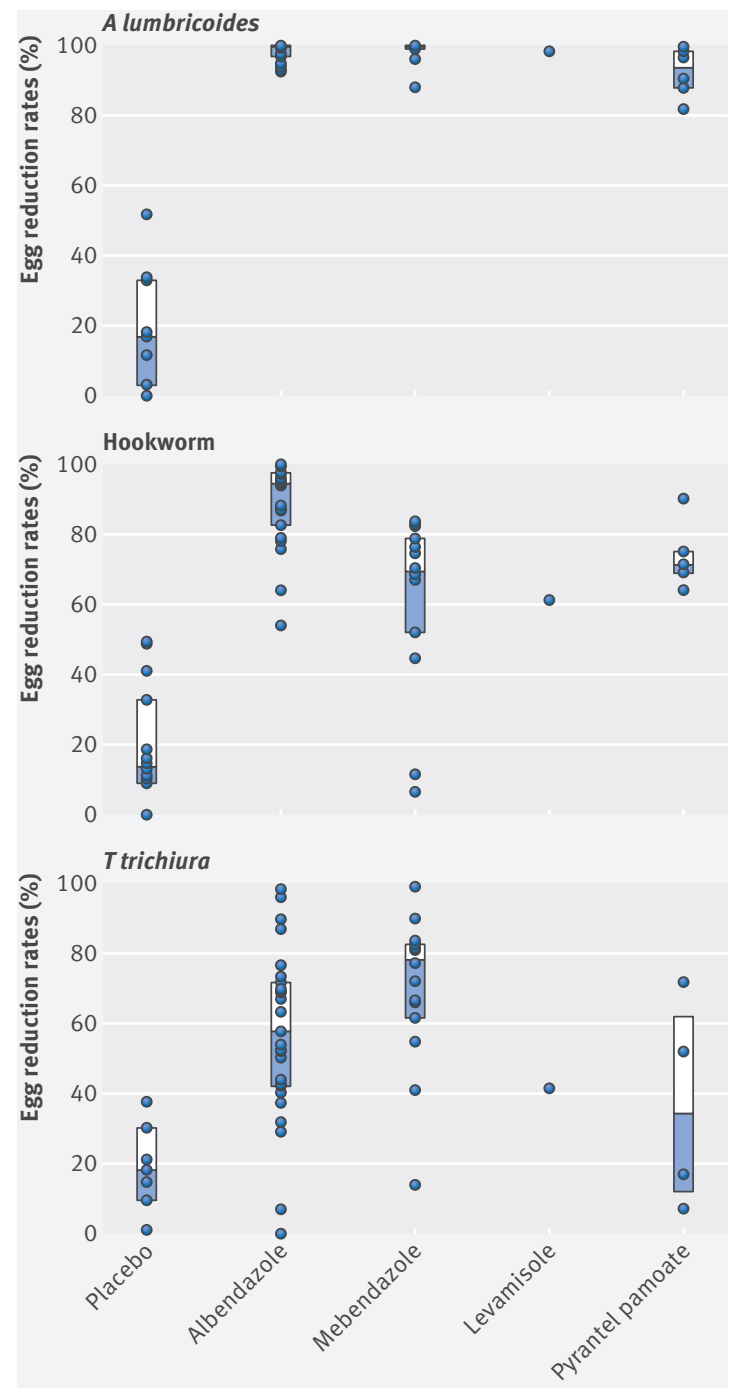

Fig 3 | Egg reduction rates for albendazole, mebendazole, levamisole, and pyrantel pamoate. Median, third quarter (white bar), second quarter (shaded bar), and individual study specific rates (solid circles) for each drug against A lumbricoides, hookworm, and $T$ trichiura. Negative values of rates were set to zero in this figure

\section{Drug efficacy against $T$ trichiura}

We used data from 38 studies (average Jadad score of 2.6), including 8841 participants positive for $T$ trichiura (table 1; table $\mathrm{N}$ in appendix 2) for analysis of cure rates of the four drugs against $T$ trichiura. Pooled estimates were based on 16 trials with one treatment, ${ }^{25} 2629-33$ 35-3840 42437374 19 studies including two treatments, ${ }^{12} 434446-51$ 53-59 626375 and three studies with three treatments. ${ }^{64-66}$

The cure rate was $8.6 \%$ (95\% confidence interval $4.1 \%$ to $17.1 \%$ ) with placebo, which was not significantly different from the rates with levamisole $(29.5 \%, 6.1 \%$ to $72.9 \%)$ and pyrantel pamoate $(20.2 \%, 7.3 \%$ to $44.7 \%$; table 1$)$. Albendazole and mebendazole showed significantly higher efficacy than placebo, with estimated cure rates of $30.7 \%$ (21.0\% to 42.5\%; $\mathrm{P}<0.001)$ and $42.1 \%$ (25.9\% to $60.2 \% ; \mathrm{P}<0.001)$, respectively. We found no significant differences among the rates of the four treatments comparing them one to one (fig 2).

We used 33 studies for analysis of the egg reduction rates $^{12} 25262931$ 35-38 4344 46-49 51 54 55-58 62-64 66 67 73-76 (fig 3). The average rate was $19.2 \%$ (95\% confidence interval $6.9 \%$ to $31.4 \%$ ) for placebo, which was significantly lower than the rates for albendazole $(\mathrm{P}<0.002)$, mebendazole $(\mathrm{P}<0.001)$, and pyrantel pamoate $(\mathrm{P}=0.008)$ but comparable with the rate for levamisole $(28.3 \%, 6.7 \%$ to $49.8 \%$; table 1$)$. The highest rate of $66.0 \%$ (54.6\% to $77.3 \%$ ) was estimated for mebendazole, which was significantly higher than the rate for albendazole $(49.9 \%, 39.0 \%$ to $60.6 \%$; $\mathrm{P}<0.001)$ and levamisole in the one to one comparison (fig 2). For pyrantel pamoate the rate was $47.5 \%$ (25.5\% to $69.6 \%)$.

Stratification by publication year (before $V$ after 2000), resulted in a significantly reduced cure rate for albendazole (44.9\% (95\% confidence interval 29.4\% to $61.5 \%) \quad v 23.7 \%$ (14.2\% to $36.7 \%)$; $\mathrm{P}=0.039$; table $\mathrm{J}$ in appendix 2). The interaction analysis, with estimates for 1995 and 2015, showed a significant decrease in cure rates for albendazole from 38.6\% (26.2\% to $52.7 \%$ ) to $16.4 \%$ (7.7\% to $31.3 \%$; $\mathrm{P}=0.027$ ) and in egg reduction rates for albendazole from $72.6 \%$ (53.7\% to $91.5 \%$ ) to $43.4 \%$ (23.5\% to $63.3 \%$; $\mathrm{P}=0.049)$ and mebendazole from $91.4 \%$ (72.9\% to $100.0 \%$ ) to $54.7 \%$ (34.6\% to $74.8 \%$; $\mathrm{P}=0.014$; table $\mathrm{L}$ in appendix 2).

\section{Discussion}

\section{Summary of key findings}

Albendazole, the most widely used anthelmintic drug against A lumbricoides and hookworm, is highly effective, both in terms of cure rates and egg reduction rates. With about 134 million doses distributed in 2015, mebendazole is the second most widely used drug for infections with soil transmitted helminths. ${ }^{77}$ It has high efficacy against $A$ lumbricoides and low activity against hookworm. Levamisole and pyrantel pamoate have high efficacy against $A$ lumbricoides, and pyrantel pamoate has moderate efficacy against hookworm. The weakness of the currently available drugs is their low efficacy against $T$ trichiura, for which mebendazole showed the best performance. This finding emphasises the urgent need for new drugs with higher efficacy against $T$ trichiura for preventive chemotherapy programmes. ${ }^{1011}$

Our review provides up to date evidence on the efficacy of the four recommended anthelmintic drugs-albendazole, mebendazole, and the less widely used levamisole and pyrantel pamoate-based on a thorough review of the literature. For the first time a network-meta analysis was applied, and we metaanalysed summary estimates on egg reduction rates, a key parameter for efficacy of anthelmintic drugs. ${ }^{18}$

\section{Strength and limitations}

The main strength of our study was the innovative data analysis including the two measures of efficacy of anthelmintic drugs: cure rates and egg reduction 
rates. By applying a network meta-analysis, we could increase the evidence by including the efficacy results of a higher number of randomised controlled trials than in a previous meta-analysis. ${ }^{11}$ Furthermore, the model from Kessels and colleagues ${ }^{24}$ allowed the inclusion of studies with only one eligible treatment arm. To assess consistency of estimates, we compared odd ratios of cure from direct and indirect comparisons of the treatments with a plot (fig $\mathrm{C}$ in appendix 3). Although some of the differences were quite large, potentially challenging the validity of the indirect comparisons, none of the differences reached significance.

The reviewed randomised controlled trials cover the past 50 years of research. This inevitably leads to huge qualitative differences among the studies, which reflects the main challenge and limitation of our analyses. There were major disparities among the included studies, which affect drug efficacy-for instance, diagnostic method, infection intensity at baseline, statistical analyses, and sample size.

The diagnostic methods used in the reviewed studies ranged from lowest sensitivity methods, such as the direct smear, up to multiple Kato-Katz thick smears, which have a reasonable sensitivity. The sensitivity of diagnostic methods is associated with the infection intensity at baseline-for example, KatoKatz has a reduced sensitivity for low egg counts. ${ }^{78}$ Both the diagnostic method and infection intensity at baseline directly influence cure rates and egg reduction rates. ${ }^{79-81}$ While the results stratified by infection intensities did not show a clear tendency for efficacy in this review, the sensitivity of the diagnostic method had an impact. Stratification of efficacy by low and moderate sensitivity of the diagnostic method significantly decreased cure rates of albendazole against $A$ lumbricoides $(\mathrm{P}=0.044)$ and hookworm $(\mathrm{P}=0.023)$. We cannot, however, explain the increase in egg reduction rates with albendazole $(\mathrm{P}=0.024)$ against $T$ trichiura (table $\mathrm{E}$ in appendix 2).

An additional limitation of the diagnostic methods (Kato-Katz, McMaster, etc) is their inability to distinguish between $A$ duodenale and $N$ americanus. Few included studies reported efficacies for specific hookworm species. The overall efficacies might differ according to the species. For example, while both hookworm species are somewhat susceptible to pyrantel pamoate, $N$ americanus is reported to be less sensitive. ${ }^{82}$ The commonly higher abundance of $N$ americanus in Africa than in Asia ${ }^{83}$ might have led to the borderline significant difference $(\mathrm{P}=0.053)$ in cure rates of pyrantel pamoate in Asia (64\%) and Africa (27\%; table $\mathrm{C}$ in appendix 2).

The network meta-analysis for egg reduction rates was limited by the lack of precision estimates in most of the studies and by the different choices of the measure of central tendency (arithmetic or geometric mean). There is an ongoing debate about advantages and disadvantages of the two systematically different means, while WHO now recommends the arithmetic mean. ${ }^{18} 84$ A few, mainly older, studies did not even report which measure of central tendency they used.
In the absence of standard errors and confidence intervals, we could not optimise the precision of meta-analytic estimates. Moreover, as arithmetic and geometric means are systematically different, we had to adjust analyses of egg reduction rates for the type of mean.

To deal with potential publication bias, we compared results of smaller and larger studies in an interaction analysis. We might have slightly overestimated the effect of albendazole against hookworm, where the cure rate showed an almost significant negative association with study size $(\mathrm{P}=0.053)$. While the cure rates of $A$ lumbricoides showed positive or stable associations with study size for all treatments, the rates of $T$ trichiura after treatment with albendazole and mebendazole slightly decreased with increasing study size, yet not significantly. Thus, we did not find consistent evidence of publication bias (table $J$ in appendix 2). The small number of available and eligible studies for levamisole is another limitation of our work. Consequently, all estimates relating to levamisole (cure rates, egg reduction rates, and odd ratios) have wide confidence intervals. Nonetheless, we present the first pooled estimates of efficacy for levamisole against hookworm, showing a low average cure rate (10.3\%, with an upper $95 \%$ confidence limit of $35.2 \%$ ), which conflicts with the fact that the drug is recommended for the treatment. ${ }^{311}$

\section{Clinical implications}

Efficacy of anthelmintic drugs is defined by cure rates and egg reduction rates. As both parameters have to be taken into consideration in comparisons of the efficacy of the drugs for each helminth species, the comparison was done qualitatively. Against A lumbricoides we found no significant differences, and all drugs had high efficacy. Albendazole had the highest efficacy for treating hookworm infections with significantly higher cure rates, followed by pyrantel pamoate, and lowest efficacy for levamisole and mebendazole when used at single oral doses. With regard to $T$ trichiura infections, mebendazole had the highest, yet only moderate, efficacy, with significantly higher egg reduction rates than albendazole. The cure rates of levamisole and pyrantel pamoate did not differ from placebo.

Moreover, after stratification by year, we found a significant decrease in cure rates for albendazole against $T$ trichiura $(\mathrm{P}=0.039)$ and a remarkable reduction against hookworm (table $\mathrm{I}$ in appendix 2). These results were even more pronounced in the interaction analysis. The cure rates for albendazole against $T$ trichiura remained significantly lower $(\mathrm{P}=0.027)$. Furthermore, egg reduction rates of albendazole $(\mathrm{p}=0.027)$ against hookworm and of albendazole $(\mathrm{P}=0.049)$ and mebendazole $(\mathrm{P}=0.014)$ against $T$ trichiura (table $\mathrm{K}$ in appendix 2 ) significantly decreased over time, which might be attributable to drug resistance. ${ }^{85}$ Several studies correlated reduced efficacies of benzimidazoles ${ }^{586470-7286}$ with emerging resistance. In 2015, more than a billion people infected with lymphatic filariasis and soil transmitted helminths 
were treated with albendazole, ${ }^{9}$ which is causing high drug pressure on parasites and might trigger drug resistance. In veterinary medicine, frequently repeated treatment with benzimidazoles has caused resistance in numerous nematode species. ${ }^{848788}$ Resistance to anthelmintic drugs in humans, however, has not yet been shown. While the reduction in efficacy could be explained by emerging resistance, other factors, related to drug regimen, diagnostics, or host and parasite characteristics, might have contributed to the reduction. ${ }^{18}$ We evaluated the impact of some potential confounders but did not assess the influence of, for example, drug quality (original versus generic drugs), change in compliance over the years, or the day to day variation in egg excretion. ${ }^{18} 89$ Hence, future randomised controlled trials should follow a harmonised design to reduce confounders, as suggested by $\mathrm{WHO}^{18}$ which will yield improved summary estimates of efficacy of anthelmintic drugs.

\section{Conclusion}

Our data confirm that the most widely used drugsalbendazole and mebendazole-have shortcomings in their efficacy profile, especially against infections with hookworm and $T$ trichiura. Alarmingly, the efficacy of albendazole and mebendazole has decreased over time. As the two most widely distributed drugs in preventive chemotherapy-albendazole and mebendazole-have been in use for almost 50 years, the threat of resistance is real and immediate. For careful monitoring of potential resistance, our summary estimates might help to revise current reference figures of efficacy. ${ }^{18}$

There is an imminent need to strengthen efforts to develop new drugs for soil transmitted helminths. Alternatively, old and new drugs-such as tribendimidine, oxantel pamoate, moxidectin, or ivermectin-with different efficacy profiles could be used in combination with the recommended drugs to successfully tackle infections with all three soil transmitted helminths. ${ }^{12} 90$ Only with an integrated approach combining improved sanitation, health education, ${ }^{91-93}$ and scaling up of research for new anthelmintic drugs and use of drug combinations for preventive chemotherapy will we achieve the ultimate goal to control soil transmitted helminth infections. Furthermore, future randomised controlled trials should follow a harmonised design to reduce confounders and yield improved summary estimates of efficacy of anthelmintic drugs.

Contributors: WM, CS, and JK conceptualised and designed the study. WM and JK conducted the study. WM and CS analysed and interpreted the data. WM and JK wrote the first draft of the paper, and CS revised the manuscript. JK is guarantor.

Funding: This review was supported by the unrestricted grant from the Swiss National Science Foundation (No 320030_14930/1).

Competing interests: All authors have completed the ICMJE uniform disclosure form at www.icmje.org/coi_disclosure.pdf and declare: this work was founded by the Swiss National Science Foundation; all other authors declare no financial relationships with any organisations that might have an interest in the submitted work in the previous three years, and no other relationships or activities that could appear to have influenced the submitted work.

Ethical approval: Not required.
Data sharing: No additional data available.

Transparency: The lead authors (WM and JK) affirm that the manuscript is an honest, accurate, and transparent account of the study being reported; that no important aspects of the study have been omitted; and that any discrepancies from the study as planned (and, if relevant, registered) have been explained.

This is an Open Access article distributed in accordance with the Creative Commons Attribution Non Commercial (CC BY-NC 4.0) license, which permits others to distribute, remix, adapt, build upon this work non-commercially, and license their derivative works on different terms, provided the original work is properly cited and the use is noncommercial. See: http://creativecommons.org/licenses/by-nc/4.0/.

1 Pullan RL, Smith JL, Jasrasaria R, Brooker SJ. Global numbers of infection and disease burden of soil transmitted helminth infections in 2010. Parasit Vectors 2014;7:37. doi:10.1186/1756-3305-7-37

2 Blanton R. Handbook of Helminthiasis for Public Health. Emerg Infect Dis 2007;13:674-5doi:10.3201/eid1304.070032.

3 Bethony J, Brooker S, Albonico M, et al. Soil-transmitted helminth infections: ascariasis, trichuriasis, and hookworm. Lancet 2006;367:1521-32. doi:10.1016/S0140-6736(06)68653-4

4 GBD 2015 DALYs and HALE Collaborators. Global, regional, and national disability-adjusted life-years (DALYs) for 315 diseases and injuries and healthy life expectancy (HALE), 1990-2015: a systematic analysis for the Global Burden of Disease Study 2015. Lancet 2016;388:1603-58. doi:10.1016/S0140-6736(16)31460-X

5 WHO. Soil-transmitted helminthiasis: eliminating soil-transmitted helminthiasis as a public health problem in children. Progress report 2001-2010 and strategic plan 2011-2020. World Health Organzation, 2012.

6 WHO. Accelerating work to overcome the global impact of neglected tropical diseases - a roadmap for implementation. World Health Organzation, 2012.

7 Crompton DWT. WHO. Preventive chemotherapy in human helminthiasis : coordinated use of anthelminthic drugs in control interventions : a manual for health professionals and programme managers. World Health Organzation, 2006.

8 WHO. Investing to overcome the global impact of neglected tropical diseases: third WHO report on neglected diseases 2015. World Health Organzation, 2015.

9 WHO. Update on the global status of implementation of preventive chemotherapy (PC). World Health Organization, 2017.

10 Keiser J, Utzinger J. The drugs we have and the drugs we need against major helminth infections. Adv Parasitol 2010;73:197-230. doi:10.1016/S0065-308X(10)73008-6

11 Keiser J, Utzinger J. Efficacy of current drugs against soil-transmitted helminth infections: systematic review and meta-analysis. IAMA 2008;299:1937-48. doi:10.1001/jama.299.16.1937.

12 Speich B, Ame SM, Ali SM, et al. Oxantel pamoate-albendazole for Trichuris trichiura infection. N Engl J Med 2014;370:610-20. doi:10.1056/NEJMoa1301956

13 Greco T, Biondi-Zoccai G, Saleh O, et al. The attractiveness of network meta-analysis: a comprehensive systematic and narrative review. Heart Lung Vessel 2015:7:133-42

14 Greco T, Zangrillo A, Biondi-Zoccai G, Landoni G. Meta-analysis: pitfalls and hints. Heart Lung Vessel 2013;5:219-25.

15 Salanti G. Indirect and mixed-treatment comparison, network, or multiple-treatments meta-analysis: many names, many benefits, many concerns for the next generation evidence synthesis tool. Res Synth Methods 2012;3:80-97. doi:10.1002/jrsm.1037

16 Salanti G, Ades AE, loannidis JP. Graphical methods and numerical summaries for presenting results from multiple-treatment metaanalysis: an overview and tutorial. / Clin Epidemiol 2011;64:163-71. doi:10.1016/j.jclinepi.2010.03.016

17 Jansen JP, Fleurence R, Devine B, et al. Interpreting indirect treatment comparisons and network meta-analysis for healthcare decision making: report of the ISPOR Task Force on Indirect Treatment Comparisons Good Research Practices: part 1. Value Health 2011;14:417-28. doi:10.1016/j.jval.2011.04.002

18 WHO. Assessing the efficacy of anthelminthic drugs against schistosomiasis and soil-transmitted helminthiases. World Health Organization, 2013.

19 Hutton B, Salanti G, Caldwell DM, et al. The PRISMA extension statement for reporting of systematic reviews incorporating network meta-analyses of health care interventions: checklist and explanations. Ann Intern Med 2015;162:777-84. doi:10.7326/M14-2385

20 WHO. WHO Model Lists of Essential Medicines. World Health Organization, 2015.

21 Halpern SH, Douglas MJ, eds. Appendix: Jadad Scale for Reporting Randomized Controlled Trials. In: Evidence-based Obstetric Anesthesia . Blackwell Publishing. 2005:237-8.

22 Cochrane Handbook for Systematic Reviews of Interventions. http:// handbook-5-1.cochrane.org/. 
23 Chaimani A, Higgins JPT, Mavridis D, Spyridonos P, Salanti G. Graphical tools for network meta-analysis in STATA. PLoS One 2013;8:e76654. doi:10.1371/journal.pone.0076654

24 Kessels AGH, ter Riet G, Puhan MA, et al. A simple regression model for network meta-analysis. OA Epidemiol 2013;Jul 22:7 doi:10.13172/2053-079X-1-1-690.

25 Adegnika AA, Zinsou JF, Issifou S, et al. Randomized, controlled, assessor-blind clinical trial to assess the efficacy of singleversus repeated-dose albendazole to treat ascaris lumbricoides, trichuris trichiura, and hookworm infection. Antimicrob Agents Chemother 2014;58:2535-40. doi:10.1128/AAC.01317-13

26 Speich B, Ali SM, Ame SM, et al. Efficacy and safety of albendazole plus ivermectin, albendazole plus mebendazole, albendazole plus oxantel pamoate, and mebendazole alone against Trichuris trichiura and concomitant soil-transmitted helminth infections: a four-arm, randomised controlled trial. Lancet Infect Dis 2015;15:277-84 doi:10.1016/S1473-3099(14)71050-3

27 Tankhiwale SR, Kukade AL, Sarmah HC, Salunkhe DS, Kulkarni AS. Single dose therapy of ascariasis--a randomized comparison of mebendazole and pyrantel. J Commun Dis 1989;21:71-4.

28 Wang BR, Wang HC, Li LW, et al. Comparative efficacy of thienpydin, pyrantel pamoate, mebendazole and albendazole in treating ascariasis and enterobiasis. Chin Med (Engl) 1987;100:928-30.

29 Belizario VY, Amarillo ME, de Leon WU, de los Reyes AE, Bugayong MG, Macatangay BJ. A comparison of the efficacy of single doses of albendazole, ivermectin, and diethylcarbamazine alone or in combinations against Ascaris and Trichuris spp. Bull World Health Organ 2003;81:35-42

30 Ndyomugyenyi R, Kabatereine N, Olsen A, Magnussen P. Efficacy of ivermectin and albendazole alone and in combination for treatment of soil-transmitted helminths in pregnancy and adverse events: a randomized open label controlled intervention trial in Masindi district, western Uganda. Am J Trop Med Hyg 2008;79:856-63.

31 Albonico M, Mathema P, Montresor A, et al. Comparative study of the quality and efficacy of originator and generic albendazole for mass treatment of soil-transmitted nematode infections in Nepal. Trans R Soc Trop Med Hyg 2007;101:454-60. doi:10.1016/j. trstmh.2006.09.003

32 Zhang D, Zhang X, Tang Z, et al. [Field trials on the efficacy of albendazole composite against intestinal nematodiasis] Zhongguo Sheng Chong Xue Yu Ji Sheng Chong Bing Za Zhi 1998:16:1-5.

33 Ioli A, Mento G, Leonaldi R, et al. Albendazole in the treatment of intestinal helminthiasis study on 140 patients. Riv Parassitol 1987;4:291-6

34 Farahmandian I, Arfaa F, Jalali H, Reza M. Comparative studies on the evaluation of the effect of new anthelminthics on various intestinal helminthiasis in Iran. Effects of anthelminthics on intestinal helminthiasis. Chemotherapy 1977;23:98-105. doi:10.1159/000221977

35 Legesse M, Erko B, Medhin G. Efficacy of alebendazole and mebendazole in the treatment of Ascaris and Trichuris infections. Ethiop Med / 2002:40:335-43.

36 Sinniah B, Sinniah D. The anthelmintic effects of pyrantel pamoate, oxantel-pyrantel pamoate, levamisole and mebendazole in the treatment of intestinal nematodes. Ann Trop Med Parasitol 1981;75:315-21. doi:10.1080/00034983.1981. 11687445

37 Ortiz JJ, Lopez Chegne N, Gargala G, Favennec L. Comparative clinical studies of nitazoxanide, albendazole and praziquantel in the treatment of ascariasis, trichuriasis and hymenolepiasis in children from Peru. Trans R Soc Trop Med Hyg 2002;96:193-6. doi:10.1016/ S0035-9203(02)90301-9

38 Zani LC, Favre TC, Pieri OS, Barbosa CS. Impact of antihelminthic treatment on infection by Ascaris lumbricoides, Trichuris trichiura and hookworms in Covas, a rural community of Pernambuco, Brazil. Rev Inst Med Trop Sao Paulo 2004;46:63-71. doi:10.1590/S003646652004000200002

39 Sarmah HC. A randomized controlled trial of pyrantel and mebendazole in children with enterobiasis and concomitant ascariasis. Indian Pediatr 1988;25:544-7.

40 Nanivadekar AS, Gadgil SD, Apte VV. By National Anthelmintic Study Group. Efficacy of levamisole, mebendazole, piperazine and pyrantel in roundworm infection. J Postgrad Med 1984;30:144-52.

41 Nontasut P, Singhasivanon V, Prarinyanuparp V, et al. Effect of single-dose albendazole and single-dose mebendazole on Necator americanus. Southeast Asian J Trop Med Public Health 1989;20:237-42.

42 Tefera E, Belay T, Mekonnen SK, Zeynudin A, Belachew T. Therapeutic efficacy of different brands of albendazole against soil transmitted helminths among students of Mendera Elementary School, Jimma, Southwest Ethiopia. Pan Afr Med J 2015;22:252. doi:10.11604/ pamj.2015.22.252.6501
43 Zu LQ, Jiang ZX, Yu SH, et al. [Treatment of soil-transmitted helminth infections by anthelmintics in current use] Zhongguo Ji Sheng Chong Xue Yu Ji Sheng Chong Bing Za Zhi 1992;10:95-9.

44 Jongsuksuntigul P, Jeradit C, Pornpattanakul S, Charanasri U. A comparative study on the efficacy of albendazole and mebendazole in the treatment of ascariasis, hookworm infection and trichuriasis. Southeast Asian J Trop Med Public Health 1993;24:724-9.

45 Lubis IN, Pasaribu S, Lubis CP. Current status of the efficacy and effectiveness of albendazole and mebendazole for the treatment of Ascaris lumbricoides in North-Western Indonesia. Asian Pac J Trop Med 2012;5:605-9. doi:10.1016/S1995-7645(12)60125-4

46 Albonico M, Smith PG, Hall A, Chwaya HM, Alawi KS, Savioli L. A randomized controlled trial comparing mebendazole and albendazole against Ascaris, Trichuris and hookworm infections. Trans R Soc Trop Med Hyg 1994;88:585-9. doi:10.1016/00359203(94)90174-0

47 Steinmann P, Utzinger J, Du Z-W, et al. Efficacy of single-dose and triple-dose albendazole and mebendazole against soil-transmitted helminths and Taenia spp.: a randomized controlled trial. PLoS One 2011;6:e25003. doi:10.1371/journal.pone.0025003

48 Sorensen E, Ismail M, Amarasinghe DK, Hettiarachchi I. The efficacy of three anthelmintic drugs given in a single dose. Ceylon Med J 1996;41:42-5

49 Albonico M, Bickle Q, Haji HJ, et al. Evaluation of the efficacy of pyrantel-oxantel for the treatment of soil-transmitted nematode infections. Trans R Soc Trop Med Hyg 2002;96:685-90. doi:10.1016/S0035-9203(02)90352-4

50 Kale 00. A comparative trial of the anthelminthic efficacy of pyrantel pamoate (Combantrin) and thiabendazole (Mintezol). Afr J Med Med Sci 1977;6:89-93.

51 Chien FL, Foon K, Hassan K. Efficacy of albendazole against the three common soil-transmitted helminthiases. Trop Biomed 1989;6:133-6.

52 El-Masry NA, Trabolsi B, Bassily S, Farid Z. Albendazole in the treatment of Ancylostoma duodenale and Ascaris lumbricoides infections. Trans R Soc Trop Med Hyg 1983;77:160-1. doi:10.1016/0035-9203(83)90056-1

53 Olds GR, King C, Hewlett J, et al. Double-blind placebo-controlled study of concurrent administration of albendazole and praziquantel in schoolchildren with schistosomiasis and geohelminths. I Infect Dis 1999;179:996-1003. doi:10.1086/314686

54 Oyediran ABOO, Oyejide CO. Double-blind comparative study of a new anthelminthic, albendazole, in the treatment of intestinal helminthes. London, England: Roval. Soc Med (Soc Med Publ Group) 1983;6:89-93.

55 Bwibo NO, Pamba HO. Double-blind comparative study of albendazole and placebo in the treatment of intestinal helminths. Roy Soc Med 1982:57:47-53.

56 Knopp S, Mohammed KA, Speich B, et al. Albendazole and mebendazole administered alone or in combination with ivermectin against Trichuris trichiura: a randomized controlled trial. Clin Infect Dis 2010;51:1420-8. doi:10.1086/657310

57 Beach MJ, Streit TG, Addiss DG, Prospere R, Roberts JM, Lammie PJ. Assessment of combined ivermectin and albendazole for treatment of intestinal helminth and Wuchereria bancrofti infections in Haitian schoolchildren. Am J Trop Med Hyg 1999;60:479-86. doi:10.4269/ ajtmh.1999.60.479

58 Soukhathammavong PA, Sayasone S, Phongluxa K, et al. Low efficacy of single-dose albendazole and mebendazole against hookworm and effect on concomitant helminth infection in Lao PDR. PLoS Negl Trop Dis 2012;6:e1417. doi:10.1371/journal.pntd.0001417

59 Legesse M, Erko B, Medhin G, et al. Comparative efficacy of albendazole and three brands of mebendazole in the treatment of ascariasis and trichuriasis. East Afr Med / 2004;81:134-8. doi:10.4314/eamj.v81i3.9142

60 Bell WJ, Nassif S. Comparison of pyrantel pamoate and piperazine phosphate in the treatment of ascariasis. Am J Trop Med Hyg 1971:20:584-8. doi:10.4269/ajtmh.1971.20.584

61 Hadju V, Stephenson LS, Abadi K, Mohammed HO, Bowman DD, Parker RS. Improvements in appetite and growth in helminthinfected schoolboys three and seven weeks after a single dose of pyrantel pamoate. Parasitology 1996;113:497-504. doi:10.1017/ S0031182000081579

62 Fox LM, Furness BW, Haser JK, et al. Tolerance and efficacy of combined diethylcarbamazine and albendazole for treatment of Wuchereria bancrofti and intestinal helminth infections in Haitian children. Am J Trop Med Hyg 2005;73:115-21

63 Speich B, Ame SM, Ali SM, et al. Efficacy and safety of nitazoxanide, albendazole, and nitazoxanide-albendazole against Trichuris trichiura infection: a randomized controlled trial. PLoS Negl Trop Dis 2012;6:e1685. doi:10.1371/journal.pntd.0001685

64 Albonico M, Bickle Q, Ramsan M, Montresor A, Savioli L, Taylor M. Efficacy of mebendazole and levamisole alone or in combination against intestinal nematode infections after repeated targeted mebendazole treatment in Zanzibar. Bull World Health Organ 2003;81:343-52. 
65 Ekenjoku AJ, Oringanje C, Meremikwu MM. Comparative efficacy of levamisole, mebendalzole and pyrantel pamoate against common intestinal nematodes among children in Calabar, South-South Nigeria. Niger J Paediatr 2013;40:217-21.

66 Sinniah B, Chew PI, Subramaniam K. A comparative trial of albendazole, mebendazole, pyrantel pamoate and oxantel pyrantel pamoate against soil-transmitted helminthiases in school children. Trop Biomed 1990;7:129-34

67 Albonico M, Smith PG, Ercole E, et al. Rate of reinfection with intestinal nematodes after treatment of children with mebendazole or albendazole in a highly endemic area. Trans R Soc Trop Med Hyg 1995;89:538-41. doi:10.1016/0035-9203(95)90101-9

68 Pugh RN, Teesdale CH, Burnham GM. Albendazole in children with hookworm infection. Ann Trop Med Parasitol 1986;80:565-7. doi:10. 1080/00034983.1986.11812067

69 Morgan P, Yamamoto M, Teesdale C, et al. Albendazole: a new treatment for hookworm. Med Q J Med Assoc Malawi 1983;1:4-5.

70 Flohr C, Tuyen LN, Lewis S, et al. Low efficacy of mebendazole against hookworm in Vietnam: two randomized controlled trials. Am I Trop Med Hyg 2007;76:732-6.

71 De Clercq D, Sacko M, Behnke J, Gilbert F, Dorny P, Vercruysse J. Failure of mebendazole in treatment of human hookworm infections in the southern region of Mali. Am J Trop Med Hyg 1997;57:25-30. doi:10.4269/ajtmh.1997.57.25

72 Sacko M, De Clercq D, Behnke JM, Gilbert FS, Dorny P, Vercruysse J. Comparison of the efficacy of mebendazole, albendazole and pyrantel in treatment of human hookworm infections in the southern region of Mali, West Africa. Trans R Soc Trop Med Hyg 1999;93:195 203. doi:10.1016/S0035-9203(99)90306-1

73 Adams VI, Lombard CI, Dhansay MA, Markus MB, Fincham JE. Efficacy of albendazole against the whipworm trichuris trichiura--a randomised, controlled trial. S Afr Med / 2004:94:972-6.

74 Sirivichayakul C, Pojiaroen-anant C, Wisetsing P, et al. A comparative trial of albendazole alone versus combination of albendazole and praziquantel for treatment of Trichuris trichiura infection. Southeast Asian I Trop Med Public Health 2001;32:297-301.

75 Namwanje $\mathrm{H}$, Kabatereine NB, Olsen A. Efficacy of single and double doses of albendazole and mebendazole alone and in combination in the treatment of Trichuris trichiura in school-age children in Uganda. Trans R Soc Trop Med Hyg 2011;105:586-90. doi:10.1016/j. trstmh.2011.07.009

76 Jackson TF, Epstein SR, Gouws E, Cheetham RF. A comparison of mebendazole and albendazole in treating children with Trichuris trichiura infection in Durban, South Africa. S Afr Med J 1998;88:880-3.

77 WHO. Preventive chemotherapy for helminth diseases: progress report 2014. Wkly Epidemiol Rec 2016:91:89-104.

78 Nikolay B, Brooker SJ, Pullan RL. Sensitivity of diagnostic tests for human soil-transmitted helminth infections: a meta-analysis in the absence of a true gold standard. Int J Parasitol 2014;44:765-74. doi:10.1016/j.ijpara.2014.05.009

79 Barda B, Zepherine H, Rinaldi L, et al. Mini-FLOTAC and Kato-Katz: helminth eggs watching on the shore of Lake Victoria. Parasit Vectors 2013:6:220 doi:10.1186/1756-3305-6-220.

80 Montresor A. Cure rate is not a valid indicator for assessing drug efficacy and impact of preventive chemotherapy interventions against schistosomiasis and soil-transmitted helminthiasis. Trans R Soc Trop Med Hyg 2011;105:361-3. doi:10.1016/j.trstmh.2011.04.003
81 Levecke B, Mekonnen Z, Albonico M, Vercruysse J. The impact of baseline faecal egg counts on the efficacy of single-dose albendazole against Trichuris trichiura. Trans R Soc Trop Med Hyg 2012;106: 128-30. doi:10.1016/j.trstmh.2011.09.007

82 Kale OO, Bammeke AO, Nwankwo EO. Field trials of pyrantel pamoate (Combantrin) in Ascaris, hookworm and Trichuris infections. Afr J Med Med Sci 1982;11:23-31

83 Loukas A, Hotez PJ, Diemert D, et al. Hookworm infection. Nat Rev Dis Primers 2016:2:16088. doi:10.1038/nrdp.2016.88

84 Kwa MS, Veenstra JG, Roos MH. Benzimidazole resistance in Haemonchus contortus is correlated with a conserved mutation at amino acid 200 in beta-tubulin isotype 1. Mol Biochem Parasitol 1994;63:299-303. doi:10.1016/01666851(94)90066-3

85 Coles GC. Drug resistance and drug tolerance in parasites. Trends Parasitol 2006;22:348-9, author reply 349. doi:10.1016/j. pt.2006.05.013

86 Reynoldson JA, Behnke JM, Pallant LJ, et al. Failure of pyrantel in treatment of human hookworm infections (Ancylostoma duodenale) in the Kimberley region of north west Australia. Acta Trop 1997;68:301-12. doi:10.1016/S0001 706X(97)00106-X

87 de Lourdes Mottier M, Prichard RK. Genetic analysis of a relationship between macrocyclic lactone and benzimidazole anthelmintic selection on Haemonchus contortus. Pharmacogenet Genomics 2008;18:129-40. doi:10.1097/ FPC.0b013e3282f4711d

88 Silvestre A, Cabaret J. Mutation in position 167 of isotype 1 betatubulin gene of Trichostrongylid nematodes: role in benzimidazole resistance?Mol Biochem Parasitol 2002;120:297-300. doi:10.1016/ S0166-6851(01)00455-8

89 Czobor P, Skolnick P. The secrets of a successful clinical trial: compliance, compliance, and compliance. Mol Interv 2011;11: 107-10. doi:10.1124/mi.11.2.8

90 Moser W, Ali SM, Ame SM, et al. Efficacy and safety of oxantel pamoate in school-aged children infected with Trichuris trichiura on Pemba Island, Tanzania: a parallel, randomised, controlled, dose-ranging study. Lancet Infect Dis 2016;16:53-60. doi:10.1016/ S1473-3099(15)00271-6

91 WHO. Water sanitation \& hygiene for accelerating and sustaining progress on neglected tropical diseases: a global strategy 2015 2020. Geneva World Health Organzation, 2015.

92 Gyorkos TW, Maheu-Giroux M, Blouin B, Casapia M. Impact of health education on soil-transmitted helminth infections in schoolchildren of the Peruvian Amazon: a cluster-randomized controlled trial. PLoS Negl Trop Dis 2013·7:e2397. doi:10.1371/ journal.pntd.0002397

93 Bieri FA, Gray DJ, Williams GM, et al. Health-education package to prevent worm infections in Chinese schoo children. N Engl / Med 2013;368:1603-12. doi:10.1056/ NEJMoa 1204885

Appendix 1: Study protocol and search terms

Appendix 2: Supplementary tables A-N Appendix 3: Supplementary figures A-C 